\title{
BM Global Health Global commitment to the prevention of intimate partner violence is not negotiable, nor is commitment to the science behind it
}

\author{
Jhumka Gupta, ${ }^{1}$ Kathryn L Falb ${ }^{2}$
}

To cite: Gupta J, Falb KL. Global commitment to the prevention of intimate partner violence is not negotiable, nor is commitment to the science behind it. BMJ Global Health 2017;2: e000305. doi:10.1136/ bmjgh-2017-000305

Received 30 January 2017 Accepted 1 February 2017

\section{SLlinked}

- http://dx.doi.org/10.1136/ bmjgh-2016-000165

\section{CrossMark}

\section{${ }^{1}$ Department of Global and Community Health, College of Health and Human Services, George Mason University, Fairfax, Virginia, USA ${ }^{2}$ International Rescue Committee, Washington, District of Columbia, USA}

\section{Correspondence to} Professor Jhumka Gupta; Jgupta4@gmu.edu
On 21 January 2017, millions of people across the globe stood up to demand that women's and girls' rights be respected and guaranteed. This call for global women's rights is especially critical at a time when the number of displaced persons totals 63.5 million-representing the highest global prevalence of displaced persons that the world has witnessed since World War II. ${ }^{1}$ Declining government stability and diminishing wealth are overwhelmingly viewed as the primary drivers of protracted and new conflicts that fuel such large-scale displacement. Yet, nearly a decade of research indicates that the status of women is also a critical predictor of a nation's security, and that women's rights must be safeguarded both in response to conflicts as well as an integral strategy towards preventing future humanitarian crises. $^{2}$ This includes gender equity in educational attainment, political representation, economic empowerment, and safety in public and within the privacy of their homes.

While equality and violence against women and girls has received high-level attention within global platforms, such as the 2030 Agenda for Sustainable Development, ${ }^{3}$ gaps remain regarding research on effective programmes that can reduce and prevent such violence from taking place. One in three women worldwide experience physical or sexual violence from a male partner (ie, intimate partner violence, hereafter IPV) at some point in their lifetime, and the health consequences have been extensively documented. ${ }^{4}$ In conflict-affected settings, IPV levels are higher, with lifetime prevalence estimates ranging from $20 \%$ to $59 \%$ within select conflict-affected countries in Sub-Saharan Africa. ${ }^{5}$ However, research and programmatic attention aiming to combat IPV in conflict settings are sparse. This is in part due to urgency in addressing basic health issues and physical infrastructure, ${ }^{6}$ donor and media prioritisation of sexual violence as a weapon of war without adequate attention to IPV, and logistical challenges of doing such rigorous research in conflict settings. ${ }^{7}$

This is precisely why findings from the Glass $e t a l$ study, published in this issue of BMJ Global Health, are such an important contribution to current understanding of preventing IPV in conflict-affected settings. Glass et al conducted a randomised controlled trial in eastern Democratic Republic of Congo on a microcredit/livestock productive asset transfer intervention. This intervention, called 'Pigs for Peace', provided programme participants ( $85 \%$ women) with a loan in the form of a piglet. Pigs for Peace participants also received ongoing support for the care and maintenance of the livestock asset. Participants representing households were randomised to delayed comparison groups. The findings showed that after 18 months, Pigs for Peace participants were more likely to report improved economic well-being and mental health, and report lower levels of IPV.

The Pigs for Peace trial is one of a small number of rigorously evaluated interventions that seek to reduce IPV by increasing economic empowerment in humanitarian settings. ${ }^{9}$ Despite this nascent state of knowledge, there is growing interest in understanding how to deliver effective women's economic empowerment programming that increases a woman's access and control over resources and her safety and well-being within the home. An important area for further exploration is determining how specific intervention components can reduce IPV in a matter that is safe and sustainable. For instance, is economic empowerment programming sufficient to reduce IPV, or must it be delivered in 
conjunction with strategies that seek to challenge and transform inequitable gender norms? The rationale behind such inquiry is that economic-only models may exacerbate risk of violence as men may use IPV to reassert their power and control over women, particularly as a woman becomes more 'empowered' in other economic realms. ${ }^{10}$ In conflict-affected settings, these concerns are especially salient. Women may take on traditional male economic roles, while men may lose their ability to provide for their family. ${ }^{7}$ These changes in gender roles may threaten men's traditional definitions of masculinity and thus serve as a catalyst for men's IPV perpetration. ${ }^{11}$ Prior work in conflict-affected settings documented reductions in IPV by combining women's economic empowerment with male engagement via gender dialogue groups that addressed equitable couple communication and joint decision making in the household. ${ }^{9}$

Notably, the Glass et al study was able to significantly reduce IPV without including an explicit gender-equity component. This is consistent with recent findings from Ecuador and Kenya, that indicate the benefits of economic empowerment (specifically, cash transfer programming) on reducing violence against women. ${ }^{12} 13$ Collectively, these findings provide emerging evidence for an alternate pathway through which economic empowerment programming may decrease IPV. Hypothesised mechanisms include reducing poverty, which in turn reduces household stress and tension within families as they are able to more easily meet basic needs. Through reduced stress and tension, IPV may be reduced. The current Pigs for Peace findings highlight the importance of more research to elucidate such pathways in order to inform strategies for the effective and safe delivery of women's economic empowerment programming in humanitarian settings. This is particularly relevant for cash transfers, as their use to aid populations affected by crisis has increased in recent years, despite important questions such as who within the household should be the target of such cash transfers to ensure women's safety. ${ }^{14}$

Furthermore, while levels of overall IPV were significantly reduced, Pigs for Peace did not yield significant reductions in physical and sexual IPV. It is, however, encouraging that emotional IPV was significantly reduced as this may be an antecedent to further reductions of other forms of IPV. More research, with longer follow-up times, is needed to determine the extent to which such positive changes are sustained in the absence of a gender-equity component. Investigations must also seek to identify the factors that can promote ongoing reductions in IPV as well as factors that may predict reversal of changes in IPV experiences. Such longitudinal research would be of particular value in conflict affected settings due to inherent instability that can rapidly shift gender norms and other structural determinants of IPV.

Future research must also seek to examine how livelihood interventions, such as the one tested by Glass et al, can be implemented in other settings, such as urban areas. Currently, over $60 \%$ of refugees reside in urban settings, ${ }^{1}$ and unique features of urban environments (eg, low social cohesion) may impact IPV dynamics and programme effectiveness. ${ }^{15}$ There is also a need for IPV intervention research with refugee populations, or migrants otherwise impacted by conflict or displacement, who reside in high-income settings. Finally, programmes such as Pigs for Peace may also have the potential to improve the status of adolescent girls or decrease the levels of violence against children within the household through similar pathways, but such research has yet to be conducted.

Glass, et al must also be congratulated on the strengths of their study. Despite the numerous challenges of conducting IPV intervention research in a conflict-affected setting, their study had minimal loss to follow-up and they were inclusive of women who face unique vulnerabilities. These women are over-represented in conflict-affected settings (eg, young widows, child brides, younger heads of households), yet are often not targeted in IPV intervention research. The research team was also able to collect data on men's IPV perpetration and women's IPV victimisation, and document changes that were concordant. The study represents a multinational collaboration between researchers and a local community based organisation, Programme d'Appui aux Initiatives Economiques. Such local collaborations are essential for obtaining community trust and engagement as well as applying local knowledge and norms towards intervention development. For instance, pigs were selected because they represented a gender neutral form of livestock transfer, thus fostering acceptance from women and men. Furthermore, collaboration with a local community-based organisation can promote intervention sustainability and integration within humanitarian settings since external donor funding is often short-lived and may quickly shift as other crises emerge.

In the current era of ongoing threats of widespread conflict and displacement, the commitment from global and local policymakers to combat violence against women with evidence-based solutions must be unwavering. As clearly voiced by the millions who participated in the Women's March on Washington and sister marches across 673 cities around the world, ${ }^{16}$ now is not the time for any nation to defund or devalue programmes and policies that serve to protect women and girls from violence. Nor is it the time to defund scientific efforts that seek to understand and address the needs of women, their families and their communities. Such rigorous scientific work must also be complemented by continued grassroots advocacy and human rights instruments. We hope that findings from Glass, et al and subsequent studies will continue to inform policymakers with rigorous scientific evidence on safe and effective approaches to reduce IPV and promote gender equity in order to improve health and national security. 
Contributors JG and KLF jointly conceptualised and wrote the editorial.

Competing interests None declared.

Provenance and peer review Commissioned; internally peer reviewed.

Data sharing statement No additional data are available.

Open Access This is an Open Access article distributed in accordance with the Creative Commons Attribution Non Commercial (CC BY-NC 4.0) license, which permits others to distribute, remix, adapt, build upon this work noncommercially, and license their derivative works on different terms, provided the original work is properly cited and the use is non-commercial. See: http:// creativecommons.org/licenses/by-nc/4.0/

\section{REFERENCES}

1. UNHCR. Global trends: forced displacement in 2015. Geneva: UNHCR, 2016.

2. Hudson VM, Ballif-Spanvill B, Caprioli M, et al. Sex and world peace. New York: Columbia University Press, 2012.

3. United Nations. Transforming our world: the 2030 agenda for Q2 sustainable development. New York, United Nations, 2015. https:// sustainabledevelopment.un.org/content/documents/21252030\% 20Agenda\%20for\%20Sustainable\%20Development\%20web.pdf (accessed 30 Jan 2017).

4. World Health Organization, London School of Hygiene and Tropical Medicine, South African Medical Research Council. Global and regional estimates of violence against women: prevalence and health effects of intimate partner violence and non-partner sexual violence. Geneva: World Health Organization, 2013.

5. Kinyanda E, Weiss HA, Mungherera M, et al. Intimate partner violence as seen in post-conflict eastern Uganda: prevalence, risk factors and mental health consequences. BMC Int Health Hum Rights 2016;16:1-11.

6. Watts C, Hossain M, Zimmerman C. War and sexual violencemental health care for survivors. N Engl J Med 2013;368:2152-4.
7. International Rescue Committee. Let me not die before my time: domestic violence in West Africa. New York, NY: IRC, 2012.

8. Glass N, Perrin N, Kohli A, et al. A randomized-controlled trial of a productive asset transfer program to improve economic and health outcomes and reduce intimate partner violence in a post-conflict setting. BMJ Global Health 2017;2:e000165.

9. Gupta J, Falb KL, Lehmann $\mathrm{H}$, et al. Gender norms and economic empowerment intervention to reduce intimate partner violence against women in rural Cote d'Ivoire: a randomized controlled pilot study. BMC Int Health Hum Rights 2013;13:46.

10. Vyas S, Watts C. How does economic empowerment affect women's risk of intimate partner violence in low and middle income countries? A systematic review of published evidence. J Int Dev 2009;21:577-602.

11. Falb KL, Annan J, King E, et al. Gender norms, poverty, and armed conflict in Cote d'lvoire: engaging men in women's social and economic empowerment programming. Health Educ Res 2014;29:1015-27.

12. Hidrobo M, Peterman A, Heise L. The effect of cash, vouchers, and food transfers on intimate partner violence: evidence from a randomized experiment in Northern Ecuador. Washington DC: International Food Policy Research Institute, 2014.

13. Haushofer J, Shapiro J. Household response to income changes: evidence from an unconditional cash transfer program in Kenya. Cambridge, MA: Massachusetts Institute of Technology Policy Brief, Massachusetts Institute of Technology, 2013.

14. Bell E. Violence against women and cash transfers in humanitarian contexts. VAWG Helpdesk Research Report. London: UKAID, 2015.

15. Cardoso LF, Gupta J, Shuman S, et al. What factors contribute to intimate partner violence against women in urban, conflict-affected settings? Qualitative findings from Abidjan, Cote d'Ivoire. J Urban Health 2016;93:364-78.

16. Adam K. Worldwide, people rally in support of Women's March on Washington. Washington Post 2017 1/21/17. https://www. washingtonpost.com/world/worldwide-people-rally-in-support-ofwomens-march-on-washington/2017/01/21/bc232bd8-de69-11e68902-610fe486791c story.html?utm term $=.49771$ b0a069f (accessed 27 Jan 2017). 